ORNL/LTR- -2015/343

\title{
Final Report: Real-Time Wavelength Discrimination for Improved Neutron Discrimination in CLYC
}

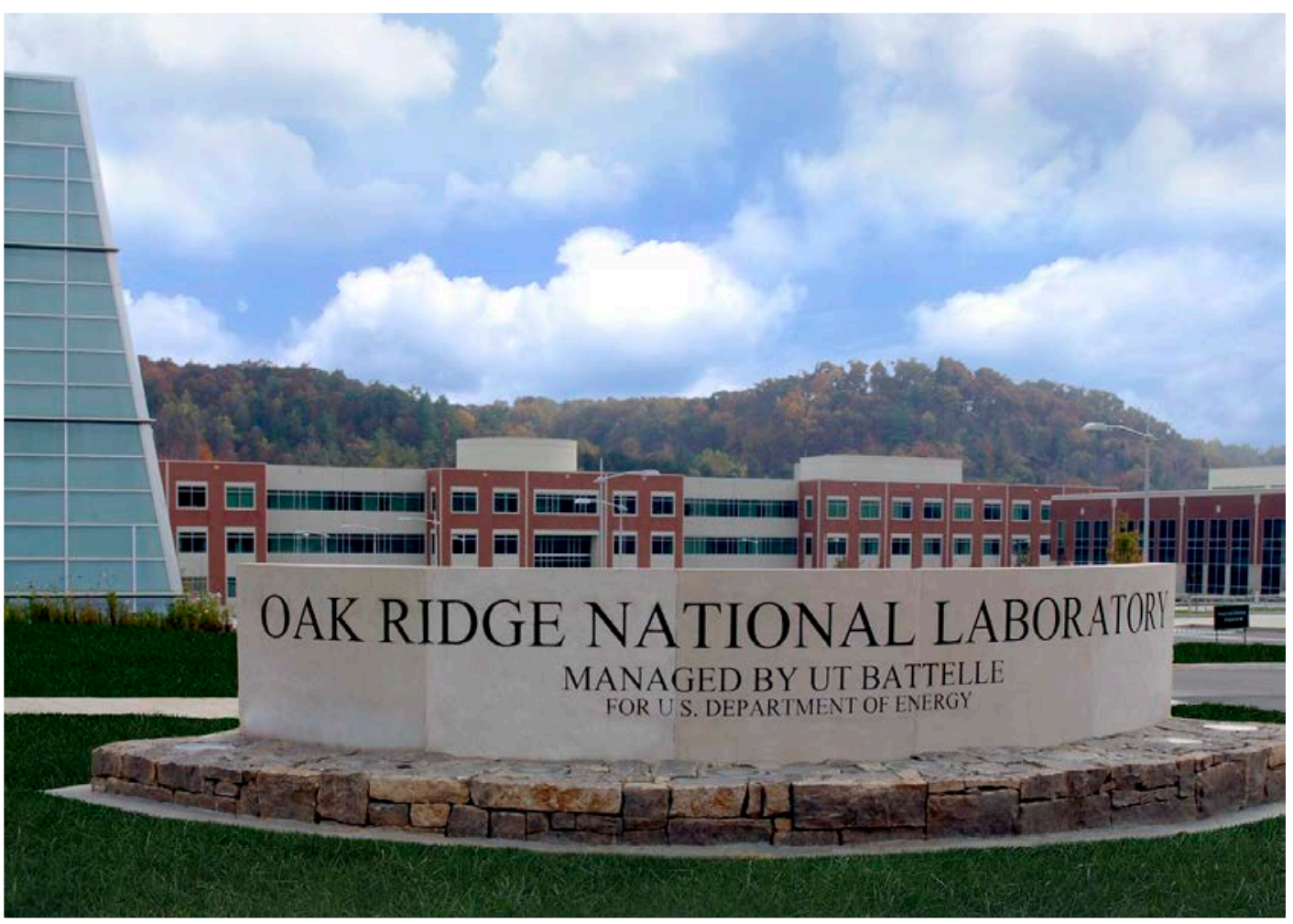

Zane W. Bell, Donald E. Hornback, Michael Z. Hu

May, 2015 
This report was prepared as an account of work sponsored by an agency of the United States Government. Neither the United States Government nor any agency thereof, nor any of their employees, makes any warranty, express or implied, or assumes any legal liability or responsibility for the accuracy, completeness, or usefulness of any information, apparatus, product, or process disclosed, or represents that its use would not infringe privately owned rights. Reference herein to any specific commercial product, process, or service by trade name, trademark, manufacturer, or otherwise, does not necessarily constitute or imply its endorsement, recommendation, or favoring by the United States Government or any agency thereof. The views and opinions of authors expressed herein do not necessarily state or reflect those of the United States Government or any agency thereof.

(reviewed in ORNL Publication Tracking System : PTS\# 56647) 
Real-Time Wavelength Discrimination for Improved Neutron Discrimination in CLYC OR12-WAVEDISC-PD2JF

The attached final report has been uploaded into the WebPMIS Summary page for this project. Please contact me if you have any additional questions or comments.

Regards,

Zane W. Bell

OR12-WAVEDISC-PD2JF Project Principal Investigator 
Final Report for DOE/NNSA Office of Defense Nuclear Nonproliferation R\&D

Real-Time Wavelength Discrimination for Improved Neutron Discrimination in CLYC PROJECT NUMBER: OR12-WAVEDISC-PD2JF

\section{How the work was done, details of analysis methods, and discussion of problems and solutions}

We investigated the effects of optical filters on the pulse shape discrimination properties of $\mathrm{Cs}_{2} \mathrm{LiYCl}_{6}$ :Ce (CLYC) scintillator crystals. By viewing the scintillation light through various optical filters, we attempted to better distinguish between neutron and gamma ray events in the crystal. We applied commercial interference and colored glass filters in addition to fabricating quantum dot (QD) filters by suspending QDs in plastic films and glass. QD filters ultimately failed because of instability of the QDs with respect to oxidation when exposed to ambient air, and the tendency of the QDs to aggregate in the plastic. Of the commercial filters, the best results were obtained with a bandpass interference filter covering the spectral region containing core-valence luminescence (CVL) light. However, the PSD response of filtered CLYC light was always poorer than the response exhibited by unfiltered light because filters always reduced the amount of light available for signal processing.

Consequently, we investigated signal processing schemes to better utilize the available information in the light pulses. Compared to the traditional charge integration method, the method of Gatti weights produced a statistically significant $16 \%$ improvement in the figure of merit (peak separation divided by sum of variances) when processing bandpass-filtered light, which translates into an improvement of 4 orders of magnitude in the fraction of gamma rays mistaken for neutrons. We also found that the use of the Kolmogorov-Smirnov statistical test to compare the shape of a light pulse to the neutron and gamma ray template shapes improved the time to identify the type of radiation by a factor of 3 over the traditional charge integration method.

The progress of work in this project, the details of the analysis methods, and discussion of problems and solutions is contained in the following documents which have been provided to DOE/NNSA/NA-22 via their WebPMIS project management system:

Deliverables:

PSD/WLD/PHD characteristics of CLYC

Task 1-3 Report

OR12-WAVEDISC-PD2JF, Task 1 Technical Deliverable

OR12WAVEDISCPD2JF 2012 Annual Report

OR12WAVEDISCPD2JF 2013 Annual Report

OR12WAVEDISCPD2JF 2014 Annual Report

Publications:

Real-Time Wavelength Discrimination for Improved Neutron Discrimination in CLYC, IEEE 2014 Nuclear Science Symposium Conference Record, paper N27-41. 
Presentations:

Real-Time Wavelength Discrimination for Improved Neutron Discrimination in CLYC, IEEE 2014 Nuclear Science Symposium, Seattle, WA, 8-15 November 2015

Quarterly Reports:

OR12-WAVEDISC-PD05 FY12Q1 through OR12-WAVEDISC-PD05 FY14Q2

\section{Retrospective view of the work, analysis, and problems/solutions at the end of the project}

The data demonstrate that selective removal of longer-wavelength components of the scintillation light affect gamma waveforms more than neutron waveforms. Since 300-313 $\mathrm{nm}$ light is absorbed by the $\mathrm{Ce}^{3+}$ activator, improvements to $\gamma$-n rejection will be more pronounced in thinner crystals. Overall, however, we found that application of optical filters worsened PSD performance because of the loss of light and poorer photon counting statistics. In this respect, the project did not achieve the hoped-for 10-fold improvement of PSD performance.

As part of the effort to understand the effects of optical filters, we examined PSD methods. We could reproduce the charge-integration method (without optical filters), as optimized by D’Olympia, (Nucl. Instr. Meth. in Phys. Res. A 714(2013)121), and demonstrate excellent PSD performance. We found that the figure of merit (difference of means of gamma ray an neutron PSD distributions divided by the sum of the standard deviations) was $5.53 \pm 0.04$. However, the figure of merit when the unfiltered Gatti weights method was used was $6.42 \pm 0.4$, which is a statistically significant difference and implies a 3-4 order of magnitude improvement in performance as measured by a ROC curve. Application of the Kolmogorov-Smirnov statistical test comparing each unfiltered pulse to average unfiltered neutron and gamma ray pulses showed that the neutron/gamma distinction could be made in approximately $200 \mathrm{~ns}$, rather than the $600 \mathrm{~ns}$ found to be optimal by D'Olympia. Additional work on optimizing pulse processing to reduce shaping should be performed so that the increased speed of decision-making can translate into higher counting rates. 